\title{
LA MULTA CIVIL EN EL ORDENAMIENTO JURÍDICO FRANCÉS: «CUANDO LAS BARBAS DE TU VECINO...»
}

\author{
The civil fine in the French Legal Order: \\ "When your neighbor's bears ..."
}

\author{
Efrén Pérez Borges \\ Doctorando en Derecho Económico y de la Empresa \\ Universidad Pontificia Comillas
}

http://dx.doi.org/10.18543/ed-67(2)-2019pp297-320

Recibido: 14.06.2019

Aceptado: 16.12 .2019

\section{Resumen}

En el ordenamiento jurídico francés, como en el español, se ha afirmado tradicionalmente la exclusiva función reparadora de la responsabilidad civil, descartando toda función preventiva o punitiva. Sin embargo, en el ámbito del derecho internacional privado se ha afirmado con rotundidad que instituciones como los daños punitivos anglosajones no son contrarias al orden público francés. De hecho, no es difícil encontrar reminiscencias preventivo-punitivas tanto en las decisiones judiciales como en determinadas instituciones legales del orden civil. Estas hallan su cúspide en la multa civil que ya se ha introducido en el ordenamiento francés, por vía del derecho de competencia, y que viene estando prevista, para el ámbito civil general, por todos los proyectos de modificación del Código Civil francés desde hace más de una década. En este sentido, la evolución seguida en Francia, tendente a expandir las finalidades del orden civil, puede servir de guía o advertencia para nuestro propio ordenamiento.

\section{Palabras clave}

Finalidad de la responsabilidad civil, multa civil, daños punitivos, prevención y punición en el orden civil francés. 


\begin{abstract}
In the French legal system, as well as in the Spanish one, it has traditionally been affirmed the exclusive redress purpose of civil liability, discarding any preventive or punitve aim. However, when it comes to private international law, it has been firmly stated that institutions like anglo saxon punitive damages are not contrary to the french public order. In fact, it is not difficult to find some preventive and punitive reminiscences both in the civil judicial decitions and in some specific civil legal institutions. These reaches it greatest expression with the civil fine, which has already been introduced in the french legal system through competition law and has been forseen by all the modification projects of the french Civil Code from more than one decade ago to present day. To this extent, the evolution followed in France, which tends to expand the purposes of civil order, may serve as a guide or a warning for our own legal system.
\end{abstract}

\title{
Keywords
}

Purposes of civil liability, civil fine, punitive damages, prevention and punition on French civil order. 


\begin{abstract}
SUMARIO: I. SÍNTESIS. II. EL ORDEN PÚBLICO FRANCÉS Y EL RECONOCIMIENTO DE SENTENCIAS EXTRANJERAS QUE CONDENAN A DAÑOS PUNITIVOS. III. LA PRÁCTICA JUDICIAL FRANCESA Y SUS REMINISCENCIAS PREVENTIVO-PUNITIVAS. IV. EL DEBATE EN LA DOCTRINA CIENTÍFICA Y LAS MEDIDAS DE ÁMBITO LEGAL CON REMINISCENCIA PREVENTIVO/PUNITIVA. 1. Las cláusulas penales y las multas coercitivas. 2. En el ámbito de la propiedad intelectual. 3. Los daños múltiples y las multas civiles. V. LOS PROYECTOS DE MODIFICACIÓN DEL CÓDIGO CIVIL FRANCÉS Y LA EVENTUAL INCORPORACIÓN DE MECANISMOS SIMILARES A LOS DESCRITOS. VI. CONCLUSIÓN. BIBLIOGRAFÍA.
\end{abstract}

\title{
I. SÍNTESIS
}

El concepto «multa civil», a los oídos de cualquier jurista patrio que se precie de una mínima ortodoxia, evocaría el mayor de los escándalos. Se trata de un híbrido; un engendro fruto del impensable cruce entre los órdenes penal o administrativo -cuya función principal es la disuasión y la punición de las conductas reprochadas por el ordenamiento-y el orden civil, orgulloso depositario de la justicia conmutativa destinada, exclusivamente, al resarcimiento de los sujetos en lid. No existiría, por tanto, campo semántico para la cópula entre el vocablo «multa» y el término «civil».

Múltiples son los inconvenientes, incluso de orden constitucional, que los más escandalizados de entre los detractores rápidamente invocarían: ¿qué ocurrirá con las garantías constitucionales más sagradas, aquellas que solo el derecho penal y el administrativo son capaces de salvaguardar? ¿Cómo puede «multarse» careciendo de tipificación, de presunción de inocencia, de estándar reforzado de prueba, etc.?

$Y$, pese a todo, la multa civil ya es una realidad en otros ordenamientos. Lo era desde hace más de una década en algunos como el argentino ${ }^{1}$, al que siempre pudimos tildar, secretamente, de lejano o ajeno a nuestra tradición jurídica (quizás porque el Océano Atlántico no solo separa las masas de tierra, sino también las lógicas jurídicas). En el ordenamiento italiano, se ven asomar ya, como se dice coloquialmente, las «orejas del lobo»: una reciente sentencia de la Corte de Casación ${ }^{2}$ afirma la

${ }^{1}$ Art. 52 bis de la Ley de Defensa del Consumidor 24240 sancionada el 22 de septiembre de 1993 y modificada mediante la Ley núm. 26.361 el 7 de marzo de 2008.

${ }^{2}$ Sentencia de las Secciones Unidas de la Corte de Casación de 5 de julio de 2017 núm. 16.601. Sobre este particular, hemos escrito en otra ocasión (PÉREZ BORGES, E., «Un giro copernicano: la plurifuncionalidad de la responsabilidad civil en Italia». Revista de Actualidad Civil LA LEY, núm. 4, (2019)). 
plurifuncionalidad de la responsabilidad civil, dejando abierta la puerta a una institución de esta índole -e incluso explicando el Alto Tribunal de aquel país, en esa resolución, cuáles deberían ser los requisitos que una hipotética medida de ese tipo debería cumplir para superar su filtro de constitucionalidad-.

Pero, sobre todo, la multa civil es una realidad próxima porque Francia, nuestro vecino más próximo y, a la sazón, «padre» reconocido de nuestro Código Civil ya la ha incorporado a su ordenamiento. Y no parece que vaya a detenerse ahí.

Por esta razón, trascendiendo el ámbito del simple Derecho Comparado, este modesto estudio sobre la multa civil francesa puede servir tanto de presagio como de advertencia. Soplan vientos de cambio y, al sentirlos, los juristas tenemos el deber no solo de analizar el derecho positivo vigente; sino también de prever y adelantar el que se proponga de lege ferenda. Debemos decidir, desde la cofa, si encaramos los vientos y aguantamos el temporal, en caso de que arrecie; o, en cambio, si izamos la vela y aprovechamos la inercia.

Pues bien, para abordar el referido estudio será necesario realizar varias «paradas». La multa civil supone, como decíamos, la confluencia -para muchos, injustificada intromisión- de materias reservadas al ámbito penal o administrativo en el orden civil. La aquiescencia con dicha institución supone, necesariamente, la atribución de finalidades distintas de las meramente reparadoras a este orden y, en particular, a la responsabilidad civil, donde hallaría aplicación la referida multa.

Por esa razón, por la finalidad preventivo-punitiva de esa institución del orden civil, resulta obligada una primera parada en otra institución, de corte jurídico anglosajón, que, al menos hasta la fecha, había abanderado y acaparado el debate sobre el acercamiento de los órdenes administrativo y penal al civil: los daños punitivos.

Asimismo, tras el análisis de la virtualidad y aceptación de esa «institución hermana» de la multa civil en el ordenamiento francés, rebuscaremos en él otras instituciones del orden civil que, según determinados sectores de la doctrina, esconden reminiscencias punitivo-preventivas. En concreto, nos detendremos en el primer supuesto de «multa civil» que, en este caso restringido a un universo muy específico de supuestos, ya se encuentra vigente y en funcionamiento en el ordenamiento galo.

Finalmente, tras la constatación del velado, pero existente y actual, contacto entre los órdenes, nos adentraremos en la evolución que ha tenido la «multa civil»-esta vez, en un ámbito mucho más generalizado- en los distintos proyectos de modificación del Código Civil francés hasta ser, a día de hoy, una posibilidad bastante susceptible de convertirse en realidad; de pasar a formar parte del derecho positivo francés. 


\section{EL ORDEN PÚBLICO FRANCÉS Y EL RECONOCIMIENTO DE SENTENCIAS EXTRANJERAS QUE CONDENAN A DAÑOS PUNITIVOS}

Como es sabido, los daños punitivos son una institución del derecho anglosajón que tiene su origen en Inglaterra ${ }^{3}$ y que pronto se extendió y obtuvo su auge en los Estados Unidos de América para atender, esencialmente $^{4}$, a tres grupos de casos $^{5}$ : (i) los supuestos en los que el cálculo del autor del ilícito o causante del daño señalen que el beneficio que obtendrá de su actuación superará el importe de la reparación; (ii) aquellos en los que existe una baja probabilidad - por la dificultad probatoria, la escasa cuantía del daño en términos del dañado individual, etc.- de que la conducta dañina sea judicialmente sancionada; y (iii) cuando quien actúa lo hace guiado por una deliberada voluntad de dañar, una especial «malicia», o incluso una absoluta ignorancia de las más elementales reglas de diligencia.

Pues bien, tradicionalmente, el ordenamiento civil galo se ha declarado abiertamente ajeno a la finalidad punitivo-preventiva de la responsabilidad civil -que sí prevén los ordenamientos anglosajones- $\mathrm{y}$, en particular, a los daños punitivos. Pese a lo anterior, sus tribunales han establecido que los daños punitivos no son contrarios, per se, a su concepto de orden público («ordre public») y, por lo tanto y hasta la fecha, resulta posible el reconocimiento en el ordenamiento francés de aquellas sentencias extranjeras que condenan a las partes a la satisfacción de daños punitivos.

Sin embargo, ello no supone la aceptación de la institución. De hecho, la Cour de Cassation francesa también ha considerado que, aunque la institución de origen anglosajón no merezca un rechazo de plano, sí requiere el análisis por los tribunales franceses de la proporcionalidad entre el daño sufrido por la

${ }^{3}$ Goldberg, J.C.P., Sebok, A. J. y Zipursky, B. C., Tort Law. Responsibilities and Redress, $3^{\text {a }}$ edición, Nueva York, Ed. Wolters Kluwer Law \& Business, 2012, pág. 519 por referencia al caso Towle v. Blake, 48 N.H. 92 (1868).

${ }^{4}$ Por supuesto, es necesario anotar que el concepto «daños punitivos» no es unívoco y que, por ejemplo, en la jurisdicción estadounidense tiene tantas acepciones como modalidades prevén los estatutos de cada estado federado. Sobre las concretas características de los daños punitivos en cada uno de ellos, léase KozIol H. Y Wilcox. V. et al., Punitive Damages: Common Law and Civil Law Perspectives», Tort and Insurance Law, vol. 25, $1^{a}$ edición, Viena, Ed. Springer, 2009, págs. 309 y siguientes.

5 Sistematizados, para los ordenamientos continentales, por KEMELMAJER DE CARLUCCI, A., «¿Conviene la introducción de los llamados «daños punitivos» en el Derecho Argentino?». Anales de la Academia Nacional de Derecho y Ciencias Sociales de Buenos Aires, núm. 31 (1993), págs. 88 y siguientes. En este sentido y para nuestro concreto ámbito, también DíEz PiCAzo, L., Fundamentos del Derecho Civil Patrimonial. Volumen V. La Responsabilidad Civil Extracontractual, $1^{\text {a }}$ edición, Madrid, Ed. Thomson-Reuters, 2011, pág. 24. 
víctima y la condena a los daños punitivos, atendiendo al caso concreto. Así lo expresó la Cour de Cassation ya en el año 2010 con total claridad ${ }^{6}$ :

«Mais attendu que si le principe d'une condamnation à des dommages-intérêts punitifs, n'est pas, en soi, contraire à l'ordre public, il en est autrement lorsque le montant alloué est disproportionné au regard du préjudice subi et des manquements aux obligations contractuelles du débiteur $(. .)$.

Pues bien, con ello comprobamos, como punto de partida, que la beligerancia de los tribunales franceses no se vuelca tanto contra la institución de los daños punitivos como contra una eventual desproporción en su aplicación. El temor a que la institución conduzca a resultados materialmente ajenos a la lógica jurídica francesa ronda las decisiones judiciales del país galo. Sin embargo, veremos a continuación que, según un sector de la doctrina, ya existe una cierta presencia soterrada de daños punitivos en su práctica judicial.

\section{LA PRÁCTICA JUDICIAL FRANCESA Y SUS REMINISCENCIAS PREVENTIVO-PUNITIVAS}

Sin perjuicio de que no es el objeto de este estudio ahondar en el contenido de las decisiones judiciales del país vecino, sí resulta interesante realizar una breve parada en ellas con un escueto ánimo comparativo.

De este modo, resulta llamativo que en el sistema francés la autoridad judicial carezca de la obligación de justificar la cuantificación del daño al que se condena a la parte ${ }^{7}$. Tal cuestión repele nuestras elementales nociones jurídicas porque, como es sabido, en nuestro ordenamiento no solo es necesario que se demuestren suficientemente los tres elementos de la responsabilidad civil (acción/omisión, daño y nexo causal) y su título de imputación subjetiva; sino que el juez debe justificar, conforme al principio constitucional de motivación de las decisiones judiciales, cómo alcanza el quantum indemnizatorio al que condena.

En Francia, sin embargo, basta con que la judicatura justifique los elementos antecedentes para que tenga una amplia capacidad discrecional a la hora de fijar el daño. De este modo, careciendo de la obligación de justificarlo, en la práctica judicial, este suele incorporar elementos que de otro modo no tendrían cabida bajo la finalidad meramente reparadora de la indemnización. A saber: (i) el comportamiento del agente del daño; (ii) la

${ }^{6}$ Decisión de la Chambre Civile 1 de la Cour de Cassation de 1 de diciembre de 2010 (09-13.303).

7 Borghetti, J.S. «Punitive damages in France» en «Punitive Damages...», op. cit., coord. Koziol H. y WiLCOX. V., págs. 65 y siguientes. 
reincidencia en la conducta; (iii) el beneficio obtenido por el causante del daño, etc. De este modo, es bastante usual que la amalgama de todos esos reproches, que el juzgador suele querer no dejar impunes, sea incorporada a la indemnización utilizando la «carcasa» del daño moral.

Tal práctica supone, de facto y para parte de la doctrina, la presencia de un cierto elemento de punición o prevención incorporado a la noción en abstracto de indemnización. Y ello, sencillamente, porque, por ejemplo, aquella «indemnización» que tiene en cuenta la reincidencia no responde a un fin exclusivamente reparador; sino que se preocupa de evitar que ese sujeto siga reincidiendo (i.e., prevención especial) y de punir el «descaro» que subyace a la comisión reincidente.

No obstante lo anterior, la presencia soterrada de esta herramienta punitivo-disuasoria, por vía del quantum del daño moral, resulta más una curiosidad y una muestra de la cercanía mental y fáctica a ese tipo de instituciones, que la aplicación consciente y razonada de una herramienta jurídica concreta y reconocida.

$\mathrm{Y}$ es que por más que el juzgador goce de una amplia discrecionalidad para introducir bajo el paraguas del daño moral todos esos conceptos, este resultará, casi siempre, razonablemente proporcionado con el daño de tipo patrimonial. Por lo tanto, los montantes a los que podría condenarse por esta vía serían razonablemente inocuos a los ojos de los acérrimos defensores de la exclusiva función resarcitoria.

\section{EL DEBATE EN LA DOCTRINA CIENTÍFICA Y LAS MEDIDAS DE ÁMBITO LEGAL CON REMINISCENCIA PREVENTIVO/ PUNITIVA}

Pese al reconocimiento ocasional de los daños punitivos en sede del derecho internacional privado -y salvo la inclusión de facto por los tribunales por la vía del quantum del daño-, la prevención y la punición han sido tradicionalmente ajenas al orden civil en Francia. Sin embargo, conforme nos adentramos en el estudio de su normativa y su doctrina científica, descubrimos algunas instituciones que, sin llegar al extremo de los daños punitivos, sí parecen arrogan al orden civil una finalidad distinta de la reparación -de hecho, en algunos casos y como veremos, la cuestión parece fuera de toda duda-.

En concreto, se comprueba entre la doctrina una creciente preocupación por una de las tipologías de supuestos para los que nacieron los daños punitivos: aquellos en los que, como decíamos, la causación de un daño, pese a su reparación, sigue reportando beneficio económico al agente y, por lo tanto, se ve perversamente incentivado a reproducir la conducta dañina. Estas conductas llegan a su zénit cuando son precedidas de un cálculo apriorístico del 
coste-beneficio de emprenderlas y justifican la honda preocupación de su doctrina.

Algunos de los primeros juristas que se adentraron en el concepto fueron STARCK, ROLAND y BOYER quienes las bautizaron como «fautes lucratives» ${ }^{8}$ y las definieron del siguiente modo:

«(...) la falta que, a pesar de los daños que el responsable tiene que pagar, y que se basan en el daño sufrido por la víctima, deja al autor un margen de beneficio suficiente como para que no tenga ninguna razón para no cometerlo»

En este sentido, más ceñido al ámbito del derecho al honor, la intimidad y la propia imagen ${ }^{9}$, FASQUELLE y Mesa las definen como $^{10}$ :

«La cuestión de las «faltas lucrativas», en primer lugar, se refiere a ciertas violaciones de la privacidad por las empresas de prensa que, a sabiendas, infringen el Artículo 9 del Código Civil después de calcular que las ganancias obtenidas de las copias adicionales vendidas serán ciertamente mayores que el coste de una posible sentencia para compensar a la víctima»

Pues bien, esta y otras «fautes lucratives» no obtienen respuesta en el ordenamiento francés, como hemos visto, por medio de los daños punitivos ni, a priori, se tratan de prevenir en el orden civil, esencialmente reparador.

${ }^{8}$ Starck, B., Roland, H. y Boyer, L., Droit civil - Les Obligations, tome 1: Responsabilité délictuelle, $5^{\text {a }}$ edición, Paris, Ed. Paris Litec, 1996, pág. 1335. Traducción propia del original: «la faute qui, malgré les dommages et intérêts que le responsable est condamné à payer - et qui sont calqués sur le préjudice subi par la victime - laisse à son auteur une marge bénéficiaire suffisante pour qu'il n'ait aucune raison de ne pas la commettre».

9 Ámbito en torno al que, por cierto, también ha girado un interesantísimo debate en nuestro país. Sobre la cuestión, cabe destacar la profundidad de la tesis de VENDRELL Cervantes, C., «Los derechos fundamentales de la personalidad incorporal y el mercado de los derechos de imagen». Tesis doctoral inédita, Universidad de Barcelona, 2010, Barcelona.

Asimismo, acerca de esta misma cuestión, entre otros muchos, léase DíEZ PICAZo, L., «La doctrina del enriquecimiento injustificado» en Dos estudios sobre el enriquecimiento sin causa, $1^{\text {a }}$ edición, Madrid, Edit. Civitas, 1988, págs. 116 y siguientes.

${ }^{10}$ FASQuelle, D. y MÉsA, R., «Les fautes lucratives et les assurances de dommages». Revue générale du droit des assurances, núm. 2005-02, (2005), pág. 351. Traducción propia del original: «La question des «fautes lucratives»évoque, en premier lieu, certaines atteintes à la vie privée réalisées par des entreprises de presse qui transgressent sciemment l'article 9 du Code civil après avoir calculé que les gains réalisés grâce aux exemplaires supplémentaires vendus seront très certainement supérieurs à ce que leur coûtera une éventuelle condamnation à indemniser la victime». 
Sin embargo, BorGHETTI, J.S. ${ }^{11}$ nos explica que podemos hallar un rastro de disuasión o punición en otros numerosos mecanismos del sistema civil francés. Así, el autor los halla en: (i) algunos mecanismos de tipo contractual; (ii) en el ámbito de la propiedad intelectual; y (iii) en otros mecanismos civiles de aplicación general. A fin de comprobar esta cuestión y de confrontar estas instituciones con sus homólogas en el ordenamiento español, las examinaremos de manera más pormenorizada.

\section{Las cláusulas penales y las multas coercitivas}

Entre los mecanismos de tipo contractual, merece la pena destacar las cláusulas penales contractuales por su similitud con la institución jurídica homónima del ordenamiento español. La lógica punitiva o preventiva de esta institución resulta clara: la cláusula penal puede desembocar en que el incumplidor de un contrato satisfaga un importe superior al daño realmente sufrido por la otra parte contractual -excediendo el ámbito resarcitorio-, señalando así una posible naturaleza preventiva o disuasoria del incumplimiento ${ }^{12}$.

Sin embargo, como el propio profesor BoRGHETTI indica, la naturaleza preventivo-punitiva de la institución viene desvirtuada por: (i) el hecho de que la cláusula penal esté previamente acordada por las partes -no impuesta por las decisiones judiciales-; y (ii) la posibilidad de que el juez la modere.

Por lo tanto, su fundamento lo encontraríamos más en la libertad contractual que en la aplicación ex lege de un mecanismo jurídico con un propósito disuasorio determinado. Asimismo, y en todo caso, la institución vendría moderada por la actividad judicial para evitar que se produzca un resultado de «excesiva» punición.

En consecuencia, pese a la finalidad última preventivo-punitiva del incumplimiento de la institución, en nuestra opinión, no podemos afirmar su

11 Borghetti, J.S. «Punitive damages in France» en «Punitive Damages...», op. cit., coord. Koziol H. Y WiLCOX. V., pág. 58 y siguientes.

${ }^{12}$ En nuestro ordenamiento, nos indica Rodriguez TAPIA, J.M., «Sobre la cláusula penal en el Código Civil». Anuario de Derecho Civil, núm. 2 (1993), pág. 550: «Sin embargo, la razón por la que llamamos penal a esta cláusula estriba en su poder disuasorio del deudor, para reforzar el vínculo contractual. Cuando el deudor sabe que la pena (por las razones que sean, incluido el mal cálculo o previsión anticipada de daños) es notablemente inferior a los daños que son previsibles, pasado un tiempo después de celebrado el contrato y antes de incumplir, no hay duda de que la pena habrá perdido toda función de refuerzo»!.

En el mismo sentido, Blanco Gómez, J. J., «La cláusula penal en las obligaciones civiles: relación entre la prestación penal, la prestación principal y el resarcimiento del daño», Ed. Dykinson, Madrid, 2002, pág. 138. 
incardinación en el ordenamiento como vía para evitar los incumplimientos contractuales, sino como máxima expresión -controlada por los tribunalesde la autonomía de la voluntad. No nos permite, por lo tanto, hablar de una finalidad preventivo-punitiva en el orden civil -ni francés ni español-stricto sensu.

En otro orden pero dentro del mismo ámbito contractual, encontramos las multas coercitivas («astreintes») que puede imponer un juez a aquel deudor que, pese a la obligación declarada por sentencia, se niega a cumplir con lo contractualmente pactado.

En este sentido, aunque la institución no tiene un origen contractual -no nace del acuerdo de voluntades- sí se aplica para el cumplimiento de una obligación de tipo contractual. Dado que el importe de esta multa coercitiva es ajeno a la reparación o cumplimiento de la obligación y es entregado al acreedor contractual, esta implicaría para el incumplidor un "excedente» económico sobre el daño reparable.

De hecho, en el nacimiento de esta institución hace más de medio siglo, gran parte de la doctrina del país galo trató de ceñirla al ámbito resarcitorio pero el Cour de Cassation señaló en $1959^{13}$ que tenía una naturaleza separada, distinta de la compensación por el retraso en el cumplimiento, y tendente a vencer la actitud obstativa al cumplimiento del contrato.

A este respecto, las astreintes sí presentan un carácter preventivo-punitivo más marcado, si bien ceñido al ámbito de la obediencia a la autoridad judicial. Cabría por lo tanto plantearse si no es, precisamente, esa otra causa la que da carta de naturaleza a la institución: ¿se pretende prevenir o castigar el incumplimiento o la desobediencia a la autoridad? La respuesta nos parece razonablemente clara: si fuese la desobediencia no existiría ninguna razón lógica por la que el importe de la astreinte fuese a parar a manos de la parte contractual incumplida.

En consecuencia, hallamos en esta institución no solo una primera referencia «válida» de disuasión y punición en el ordenamiento civil francés; sino una con cierta similitud con los «daños punitivos».

\section{En el ámbito de la propiedad intelectual}

En el ordenamiento francés también hallamos medidas del ámbito de la propiedad intelectual que, por su similitud con las del ámbito español, evitaremos reproducir ${ }^{14}$. Baste indicar que, como en el supuesto patrio, se permite

13 Sentencia de La Cour de Cassation de 29 de octubre de 1959.

14 Vide art. 140.2 Real Decreto Legislativo 1/1996, de 12 de abril, por el que se aprueba el texto refundido de la Ley de Propiedad Intelectual. 
calcular la «indemnización» del daño por vía del beneficio obtenido por el infractor; lo que despierta el recelo de los acérrimos defensores de un cálculo del daño más «tradicional».

En este sentido, el debate entablado es muy similar al que tiene lugar respecto al honor, la intimidad y la propia imagen ${ }^{15}$. Baste con indicar en esta sede que los sectores doctrinales patrios oscilan entre la atribución de la naturaleza de la medida al lucro cesante, al Derecho de Enriquecimiento o a una específica medida preventivo-punitiva de la infracción (un «daño punitivo larvado», como lo denominan algunos). Y es que los defensores de esta última opción «hacen del ataque su mejor defensa» y cuestionan cómo podría justificarse que el beneficio obtenido por el infractor del derecho de propiedad intelectual es uno que habría podido obtener su titular si no cuenta con los mismos medios (a fin de justificar así el trasvase en el Derecho de Enriquecimiento o la acreditación del daño en el lucro cesante).

Siendo un debate, como se ha dicho, extenso -y casi manido- sobre el que poco podemos aportar, preferimos centrarnos a continuación en las figuras innovadoras que, con mucha menos duda, sí incorporan elementos preventivo-punitivos al ordenamiento civil.

\section{Los daños múltiples y las multas civiles}

Por último, de entre todas las instituciones del ordenamiento francés con reminiscencias preventivo-punitivas, las más interesantes resultan: (i) los daños múltiples; y (ii) las multas civiles («amende civile»).

Los primeros consisten en la imposición del doble del interés legal a aquella compañía aseguradora que, debiendo poner a disposición del asegurado la suma de la indemnización en una fecha determinada, no lo hace.

Se pretende de este modo disuadir a las compañías de seguro de la tentación de alargar el pago ante un siniestro. Así, tal y como ocurre en nuestro ordenamiento, si el tipo de interés legal viene a satisfacer el daño causado por el tiempo en que se ha privado al dañado del montante indemnizatorio, su duplo no puede en ningún caso verse justificado por ese mismo concepto. Y es que el tipo de interés legal del dinero viene fijado legislativamente, precisamente, bajo la previsión del «valor» del dinero en el tiempo. Ese «valor» no se incrementa por el solo hecho de que un concreto deudor, en este caso la aseguradora, se niegue a pagarlo.

No obstante todo lo anterior y la incapacidad que hallamos para encontrarle una lógica no punitiva o preventiva, BORGUETTI señala que, a la postre, nos encontramos ante una cuantía disuasoria casi irrisoria y, por lo tanto, de

${ }^{15}$ Vide ut supra nota 9. 
escasa relevancia para el ordenamiento: incapaz de perturbar, por sí sola, el orden esencialmente reparador de la responsabilidad civil.

Consideración netamente distinta merece el supuesto de las «multas civiles» («amende civile») que da título el presente estudio.

Antes de proseguir, es conveniente apuntar cuál es el destino del importe satisfecho por estas multas civiles descritas en el ordenamiento francés. A diferencia de los daños punitivos -en la mayoría de sus manifestaciones, aunque no en todas- el importe de la multa civil se destina a las arcas del Estado ${ }^{16}$, evitando así cualquier acusación de enriquecimiento injustificado del dañado.

$\mathrm{Y}$ es que en el ordenamiento francés encontramos las siguientes:

(i) Quien, habiendo sido apercibido de su deber de decir verdad ante los tribunales de justicia, no lo hiciera ${ }^{17}$.

(ii) Otras multas de tipo procesal como, por ejemplo, por la interposición de recursos con ánimo dilatorio o abusivo ${ }^{18}$.

En este sentido, la naturaleza civil de estas multas reside en el orden jurisdiccional en el que son impuestas $y$, a nuestro juicio, tienen su fundamento en la proscripción de la mala fe procesal o la desobediencia a la autoridad. Su naturaleza procesal, vinculada con la autoridad y el respeto formal al proceso, hace especialmente complicado erigirlas en supuestos capaces de subvertir la afirmación de la finalidad esencialmente reparadora del orden civil.

Sin embargo, en este sentido, no encontramos indicios de una naturaleza distinta a la de las multas que también se pueden imponer en nuestro ordenamiento por un tribunal a las partes procesales o los testigos por las más diversas razones ${ }^{19}$.

${ }^{16}$ Borghetti, J.S. en «Punitive Damages...», op. cit. pág. 61.

17 Art. 10 del Código Civil francés y 207 del Código de Enjuiciamiento Civil francés: «Todos están obligados a prestar su colaboración a la justicia a fin de manifestar la verdad. Aquél que sin motivo legítimo se sustraiga a esta obligación habiendo sido legalmente requerido a ello, podrá ser obligado a satisfacerla, si es necesario bajo pena de multa o sanción civil.»

18 Arts. 581 y 628 del Código de Enjuiciamiento Civil francés.

19 Vide e.g. arts. 270.2 in fine (multa por la presentación extemporánea de pruebas); 283 bis h d y 283 bis $\mathrm{k} 2$ (multas ambas relativas al acceso a las fuentes de prueba y su práctica, con, por cierto, una cuantía nada desdeñable); 286.4 (multa por el ánimo dilatorio o mala fe procesal en la alegación de hechos nuevos o de nueva noticia); 288.1 (multa por no ejecución de la prueba en el tiempo previsto); 292.1 y 4 (multa por no comparecer la parte citada al interrogatorio o los testigos); art. 320 (multa por la impugnación temeraria de documentos); art. 344.2 (multa por temeridad en la tacha de testigos); 381.2 (multa por la falta de envío del pliego de preguntas por escrito); todos ellos de la Ley 1/2000 de Enjuiciamiento Civil española. 
Aunque las multas de tipo procesal no sean el objeto central de este estudio, sí resulta interesante comprobar que son el único tipo de multa civil que, en esencia, compartimos con el país francés. En este sentido, cabe preguntarse qué diferencia estas multas de tipo procesal con aquellas que castigan comportamientos materiales. Sería legítimo preguntarse por qué no hallamos impedimentos en la aplicación de aquéllas, pero, para un amplio sector de la doctrina española, resulta inconcebible una multa impuesta por un tribunal civil respecto de incumplimientos materiales, de fondo.

(iii) Para sancionar la violación de los deberes profesionales de algunos cargos públicos (e.g. registradores) $)^{20}$.

(iv) Por el incumplimiento de las obligaciones de tutela ${ }^{21}$.

En este caso, además, resulta llamativa la prohibición expresa de recurso de la resolución que acuerde la multa ${ }^{22}$. Se convierte así no solo en un ejemplo claro de punición civil, sino, además, en uno especialmente expeditivo y sumario.

(v) Frente a prácticas colusorias e infractoras de deberes inherentes al ámbito empresarial y de la competencia.

Resulta, con diferencia, el supuesto más interesante y merecedor de nuestra atención. Y ello porque la multa a imponer por el tribunal no trae causa, a diferencia, de la mayoría de los casos anteriores, de un comportamiento procesal o es tan específica que no permite generalizar la idea de punición-prevención de una conducta. En cambio, esta última multa civil se asienta en causas materiales y de fondo, ni accesorias ni cualitativamente irrelevantes.

En efecto, el art. L442-6 del Código de Comercio francés recoge, en su apartado I, un catálogo de actuaciones que «comprometerá(n) la responsabilidad de su autor y le obligará(n) a reparar el daño causado» ${ }^{23}$.

$« 1^{\circ}$ Obtener o intentar obtener de la otra parte en la negociación cualquier ventaja que no corresponda a ningún servicio comercial efectivamente prestado o manifiestamente desproporcionado con relación al valor del servicio prestado (...);

$2^{\circ}$ Someter o intentar someter a un colaborador comercial a obligaciones que provoquen un desequilibrio significativo en los derechos y obligaciones de las partes;

\footnotetext{
20 Art. 50 del Código Civil francés.

${ }^{21}$ Art. 395 del Código Civil francés en relación con el 1.230 del Código de Enjuiciamiento Civil francés.

${ }^{22}$ Art. 1.230 del Código de Enjuiciamiento Civil francés: «Las resoluciones que las impongan no serán susceptibles del recurso previsto en el artículo 1.215».

${ }_{23}$ Art. L442-6 del Código de Comercio francés. Traducción: Victoria de Diego Ángeles y Fernando Feldman.
} 
$3^{\circ}$ Obtener o intentar obtener una ventaja como condición previa para realizar pedidos, sin acompañarlo de un compromiso escrito sobre un volumen de compra proporcionado y, eventualmente, de un servicio solicitado por el proveedor y que hubiera sido objeto de un acuerdo escrito;

$4^{\circ}$ Obtener o intentar obtener, bajo la amenaza de ruptura brutal, total o parcial de las relaciones comerciales, condiciones manifiestamente abusivas respecto a los precios, los plazos de pago, las condiciones de venta o los servicios no correspondientes a las obligaciones de compra y de venta;

$5^{\circ}$ Romper bruscamente, incluso de forma parcial, una relación comercial establecida sin previo aviso escrito que tenga en cuenta la duración de la relación comercial y que respete el plazo mínimo establecido para dicho aviso por los usos y costumbres del comercio para acuerdos interprofesionales. (...);

$6^{\circ}$ Participar directa o indirectamente en la infracción de la prohibición de reventa fuera de la red asignada al distribuidor vinculado por un acuerdo de distribución selectiva o exclusiva no válido por las normas aplicables del derecho de libre competencia;

$7^{\circ}$ Someter a un colaborador a condiciones de pago que no cumplan el límite establecido en el párrafo noveno del Artículo L. 441-6 o que sean manifiestamente abusivas, teniendo en cuenta las buenas prácticas y los usos comerciales, y que se aparten, en detrimento del acreedor, sin razón objetiva, del plazo indicado en el párrafo octavo del Artículo L. 441-6. Será considerado especialmente abusivo por parte del deudor, el hecho de solicitar al acreedor, sin razón objetiva, que posponga la fecha de emisión de la factura;

$8^{\circ}$ Proceder a rechazar o devolver mercancías o deducir de oficio del importe de la factura establecida por el proveedor las penalizaciones o descuentos correspondientes al incumplimiento de una fecha de entrega o a la no conformidad de las mercancías, cuando la deuda no sea cierta, líquida y exigible, o el proveedor no haya tenido la oportunidad de comprobar la realidad del motivo correspondiente;

$9^{\circ}$ No comunicar sus condiciones generales de venta, en las condiciones previstas en el Artículo L. 441-6 a cualquier comprador de productos o cualquier solicitante de prestaciones de servicios que lo hubiera solicitado para el ejercicio de una actividad profesional;

$10^{\circ}$ Negarse a mencionar en el etiquetado de un producto vendido bajo marca de distribuidor el nombre y la dirección del fabricante cuando este lo hubiera solicitado de conformidad con el Artículo L. 112-6 del Código de Consumo;

$11^{\circ}$ Anunciar precios fuera de los lugares de venta, para fruta o verdura fresca, sin cumplir las normas definidas en los puntos II y III del Artículo L. 441-2 del presente código;

$12^{\circ}$ No adjuntar a la fruta y verdura fresca destinada a la venta o la reventa en un profesional establecido en Francia, para su transporte por el territorio nacional, el documento previsto en el Artículo L. 441-3-1;

$13^{\circ}$ Beneficiarse de descuentos, rebajas y reintegros en la compra de fruta y verdura fresca infringiendo el Artículo L. 441-2-2.» 
Pues bien, una vez fijado el catálogo de conductas proscritas ${ }^{24}$, el apartado III del artículo habilita a: (i) cualquier interesado; y (ii) una serie de organismos públicos (en concreto, el ministerio fiscal, el ministerio de economía o la autoridad de competencia) al ejercicio de acciones con fundamento en las susodichas prácticas, incluyendo, por supuesto, la acción de reparación del daño causado por ellas ${ }^{25}$.

${ }^{24}$ Resulta sumamente interesante comprobar la dicción literal de este catálogo de prácticas. Y ello porque uno de los principales escollos que suele encontrar la institución de la «multa civil» es el principio de tipicidad: en nuestro ordenamiento al menos, se exige una concreción máxima en la definición de las conductas merecedoras de un reproche de tipo punitivo y es uno de los argumentos normalmente esgrimidos para alejarlos del ámbito de la responsabilidad civil, generalmente de carácter abierto, no tasado.

Pues bien, comprobamos que el catálogo de prácticas del art. L442-6 del Código de Comercio incluye, en algunas ocasiones, conductas bastante «abiertas» (e.g. apartados 1, 2, 4 y 7) con expresiones como:

«(...) obtener (...) cualquier ventaja que no corresponda a ningún servicio comercial»; "someter (...) a obligaciones que provoquen un desequilibrio», parece ser que de cualquier tipo; «obtener (...) condiciones manifiestamente abusivas», cualesquiera que estas sean; o «romper bruscamente (...) una relación comercial establecida sin previo aviso escrito que tenga en cuenta la duración de la relación comercial y que respete el plazo mínimo establecido para dicho aviso por los usos y costumbres del comercio», sin que quepa conocerse cuál es ese plazo con exactitud.

Por el contrario, otras conductas del precepto son mucho más concretas, estrechando así la tipificación de la conducta (e.g. apartados 3, 6 y 8 al 13).

Sin embargo, pese a lo anterior, lo cierto es que la «tipificación abierta» de las conductas merecedoras del reproche civil y su posible conflicto con los principios constitucionales no ha supuesto un inconveniente para el legislador galo. Tampoco lo ha sido para los tribunales de aquel país que, como veremos más adelante, han refrendado el precepto en varias ocasiones.

${ }_{25}$ Resulta también interesante, desde una óptica civil, entender cómo un organismo público cuenta con legitimación activa para exigir al causante la reparación del daño ocasionado a un tercero que no forma parte del procedimiento. Y es que, al habilitar a los ministerios y a la autoridad de competencia a «reclamar el resarcimiento de los perjuicios sufridos» cabe preguntarnos si se refiere al perjuicio sufrido por estos organismos (como mucho, abstracto o difuso) o el de los particulares afectados. Por más que la conducta dañina entre dentro del ámbito de las competencias del órgano administrativo, esta última posibilidad parece orillar las reglas más elementales de nuestro ordenamiento. No ahondaremos en tal posibilidad, por exceder el ámbito de este estudio, pero sí interesa apuntar al menos la posibilidad de que este mecanismo de «cuasisubrogación» o de tutela pública de intereses privados podría suplir la falta de iniciativa privada (apatía racional, regla de minimis, etc.) en algunos casos en los que los dañados individuales no demandan. La idoneidad de la medida, sin embargo, es una cuestión muy diferente. 
Lo realmente novedoso del precepto es que, en ese procedimiento, el ministerio de economía y el ministerio fiscal ${ }^{26}$ pueden solicitar: (i) el cese de las prácticas contrarias a la norma; (ii) la nulidad de cláusulas contractuales que incurran en alguna de las prohibiciones; y (iii) la imposición de una multa civil de hasta 5 millones de euros ${ }^{27}$-susceptible de un incremento ${ }^{28}$ hasta el triple de la cantidad indebidamente pagada, el beneficio obtenido por la práctica o el $5 \%$ de la facturación de la empresa en el último ejercicio ${ }^{29}$-.

Pues bien, atendido el precepto legal, resulta también relevante examinar la jurisprudencia del país galo en la que se describe su naturaleza. Así, el Consejo Constitucional francés expresó que, a la multa civil, le son aplicables los principios de presunción de inocencia y de responsabilidad por los propios actos, al tratarse de una «sanción pecuniaria no penal»"

«En premier lieu, l'amende civile instituée par les dispositions contestées, qui sanctionne les pratiques restrictives de concurrence, a la nature d'une sanction pécuniaire. Le principe selon lequel nul n'est punissable que de son propre fait lui est applicable.»

$[\ldots]$

10. Les dispositions contestées permettent qu'une sanction pécuniaire non pénale (...) «

Así las cosas, nos hallamos ante el supuesto de «multa civil» más interesante del ordenamiento galo por dos razones:

${ }^{26}$ Nótese que se ha privado de esa legitimación activa, tras el inicio del procedimiento, tanto al interesado como a la autoridad de competencia. Los motivos de tal decisión nos son desconocidos.

${ }^{27}$ En la redacción original anterior a la ley núm. 2016-1691 de 9 de diciembre de 2016 el importe de la multa ascendía a 2 millones. Sin embargo, el legislador consideró insuficiente ese importe para elevarlo a 5 millones. Asimismo, en su redacción previa a la ley núm. 2015-990 de 6 de agosto de 2015, tampoco se preveía el incremento de la sanción por referencia al beneficio obtenido o el volumen de facturación de la empresa; todo lo cual nos da una idea de la tendencia y preocupación del legislador francés.

${ }^{28}$ Resulta curioso comprobar cómo los límites establecidos en el ordenamiento francés para esta multa coercitiva son prácticamente idénticos a los que ya establecieran 16 estados de EEUU a los punitive damages. En efecto, los límites en derecho francés se configuran: (i) por un múltiplo de la cantidad dejada de pagar (o daño); (ii) el beneficio obtenido por la concreta práctica; y (iii) un importe relativo a la facturación de la empresa. Asimismo, los límites en esos 16 estados se basan en que los punitive damages no puede rebasar: (i) el triple de la indemnización compensatoria; (ii) los ingresos brutos del demandado; o (iii) una cuantía fija de 5 millones de dólares (Kozıol H. Y WiLCoX. V. et al., Punitive Damages..., op.cit, pág. 143). Se comprueba así la similitud, siquiera teleológica, entre las figuras.

${ }^{29}$ Es de hacer notar que el precepto fue avalado por el Conseil Constitutionnel en su Décision núm. 2011-126 QPC de 13 de mayo de 2011.

${ }^{30}$ Décision del Conseil Constitutionnel núm. 2016-542 QPC de 18 de mayo de 2016. 
a. Por un lado, porque el procedimiento civil puede ser iniciado por los particulares y, una vez suscitado este, si consiguen la personación del Ministerio de Economía o el Ministerio Fiscal, podría derivarse la referida multa civil de la iniciativa del afectado, siquiera de forma mediata.

En nuestra opinión, no se trata de una cuestión baladí. Aunque la legitimación para solicitar la multa al tribunal sigue residiendo en organismos públicos, sujetos a su principio de discrecionalidad (de forma similar a como ocurre en el derecho administrativo), el que los particulares tengan la oportunidad de suscitar la cuestión en sede de un tribunal civil es un avance y un freno, al menos estético, si se quiere, a la discrecionalidad administrativa que, en ocasiones, deja «impunes» muchas conductas proscritas.

Asimismo, sin perjuicio del criterio seguido por el legislador francés, nada parece indicar que dicha legitimación deba residir, necesariamente, en los dos organismos públicos escogidos. En buena lógica, el legislador podría haber optado por extender esa legitimación a la autoridad de competencia (que sí figura en el apartado II) e incluso a los particulares. Y ello sin que, materialmente, variase la naturaleza del precepto (la naturaleza de la institución sería idéntica, las garantías para el demandado no variarían, el juzgador seguiría estando en disposición de aceptarla o no, etc.).

b. Por otro lado, la multa civil del Código de Comercio francés también resulta especialmente importante por: (i) su cuantía; y (ii) el tipo de casos que pretende solventar (muy relacionados con las «fautes lucratives» estudiadas anteriormente).

En lo relativo a la cuantía, la previsión de una multa de 5 millones de euros con la posibilidad de aumentar en relación con lo lucrativa que haya sido la conducta supone un salto cualitativo (por su trascendencia simbólica) y cuantitativo respecto del resto de precedentes de multa civil.

Si con los daños múltiples BorguETTI desterraba su estudio y consideración por su escasa significación, la multa del art. L442-6 no puede ser desdeñada. Y es que tanto el montante absoluto ( 5 millones) como el relativo, con sus sucesivos aumentos, se convierten, a nuestro juicio, en una auténtica declaración de intenciones del legislador: «no se tolerará la causación de un daño del que se obtenga lucro».

Asimismo, aunque la concreta tipificación de las conductas es, a nuestro entender, una cuestión razonablemente irrelevante ${ }^{31}$, sí merece la

${ }^{31}$ Entiéndase que, a nuestro juicio, resulta relevante si nos hallamos ante la previsión de conductas muy concretas o si, en cambio, se «tipifican» supuestos abiertos capaces de 
pena comprobar que no solo encontramos entre ellas prácticas colusorias, más propias del Derecho de la Competencia, sino también prácticas que se adentran en el ámbito más netamente civil (como es la ruptura sorpresiva de una relación estable de negocio o el rechazo o devolución de mercancías bajo determinadas circunstancias).

En definitiva, esta multa sienta un precedente sumamente interesante en uno de los ordenamientos de los países de nuestro entorno. Como veremos en el siguiente apartado, tampoco ha sido la única vez que el legislador se lo ha planteado.

\section{LOS PROYECTOS DE MODIFICACIÓN DEL CÓDIGO CIVIL FRANCÉS Y LA EVENTUAL INCORPORACIÓN DE MECANISMOS SIMILARES A LOS DESCRITOS}

Atendido todo lo anterior y, en particular, el precedente del Código de Comercio, no es de extrañar que en la última década se hayan multiplicado las voces y los intentos de incorporar a la legislación gala instrumentos de aplicación más genérica que el Art. L442-6 del Código de Comercio y que solventen supuestos de hecho similares.

En este sentido, encontramos tres iniciativas que, aunque a la fecha de este estudio no hayan sido recibidas por la legislación francesa, resultan de suma importancia: se tata del Project Catalá, que pretendió la incorporación de los daños punitivos stricto sensu; el Project Terré, con una visión más moderada; $y$ el más reciente Anteproyecto de Reforma del Código Civil que incorpora una multa civil muy similar a la ya estudiada.

En efecto, en el año 2006, se publicó el Proyecto de Reforma del Código Civil francés realizado por el Prof. Catalá junto con otros 34 juristas, en su mayoría, del ámbito académico. En ese texto, lejos de prohibirse, se preveían los daños punitivos en el ordenamiento francés. Así se hacía en el art. 137132:

«El autor de una culpa manifiestamente deliberada, y principalmente de una culpa lucrativa, puede ser condenado, además de a la indemnización de los daños y perjuicios compensatorios, a la indemnización de los daños punitivos, de los cuales el juez tiene la facultad de hacer beneficiar en una parte al Tesoro público. La decisión del juez de otorgar tal indemnización de daños y perjuicios debe ser especialmente motivada y su

englobar distintos tipos de actuaciones. Y ello por su importancia desde un punto de vista de técnica legislativa y cumplimiento de los requisitos constitucionalmente exigidos. Pero desde un punto de vista material, resulta razonablemente irrelevante si se está multando un «trust» o la ruptura intencionada de negociaciones.

${ }^{32}$ Avant-Projet Català presentado ente el Ministro de justicia francés en septiembre de 2005 . 
montante se distingue del de los otros daños y perjuicios acordados a la víctima. Los daños punitivos no son asegurables. $\left.{ }^{33}\right\rangle$

En este sentido, es necesario apuntar que el concepto de «culpa lucrativa» se aproxima al elemento subjetivo que subyace a las fautes homónimas. Se definen, por tanto, como «la hipótesis en la que el sujeto quiera lograr un beneficio superior a la condena pecuniaria posible» ${ }^{34}$.

Sin embargo, aunque este proyecto causó una honda impresión inicial, la incorporación de su propuesta a la normativa positiva, siempre postergada, parece cada vez menos probable. Sirve, sin embargo, para examinar cómo un grupo nada desdeñable de juristas franceses estuvieron a punto de incorporar al ordenamiento francés unos daños punitivos con bastante similitud con la institución anglosajona.

Entre los años 2009 y 2013, se fraguó otro proyecto de modernización por el profesor François Terré en el que se abordó la cuestión desde una óptica diferente. En él, se pretendía otorgar al juez la capacidad de elegir entre dos modos de «resarcimiento»: el daño sufrido o el beneficio obtenido por el causante con su conducta ${ }^{35}$.

De este modo, expresaba en su artículo $54^{36}$ :

«Cuando el autor del daño haya cometido intencionalmente una falta lucrativa, el juez tendrá el poder de otorgar, mediante una decisión especialmente motivada, la cantidad de beneficios retirados por el acusado en lugar de la indemnización por el daño sufrido por el demandante.

El montante que exceda a la que hubiera recibido el demandante por danos compensatorios no puede ser cubierto por un seguro de responsabilidad»

Como resulta evidente, sin tratarse de daños punitivos, la iniciativa del Project Terré guarda muchas similitudes con la institución y, sobre todo, supone una clara opción por exceder el ámbito reparador de la responsabilidad civil y adentrarse en el preventivo-punitivo.

${ }^{33}$ Traducción contenida en CABAnillas SÁncheZ, A., «El Anteproyecto francés de reforma del Derecho de obligaciones y del Derecho de la prescripción. (Estudio preliminar y traducción)». Anuario de Derecho Civil, tomo LX, fasc. II (2007).

${ }^{34}$ Ferrante, Alfredo, «Una primera aproximación al Avant-Projet CATALA y a la nueva responsabilidad civil en el Derecho Francés», InDret 1/2008, Revista para el Análisis del Derecho, Barcelona (2008), pág. 12.

${ }_{35}$ Con una fórmula que ya nos resulta similar tanto en el ordenamiento francés como en el español (vide ut supra apartado $I V d$ ).

${ }_{36}$ Traducción propia del art. 54 del Project Terré original: «Lorsque l'auteur du dommage aura commis intentionnellement une faute lucrative, le juge aura la faculté d'accorder, par une décision spécialement motivée, le montant du profit retiré par le défendeur plutôt que la réparation du préjudice subi par le demandeur. La part excédant la somme qu'aurait reçue le demandeur au titre des dommages-intérêts compensatoires ne peut être couverte par une assurance de responsabilité». 
Así las cosas, el tiempo transcurrido desde la publicación de estos proyectos, la centralización de los esfuerzos de los sucesivos gobiernos galos en el ámbito de la modernización de las obligaciones y los contratos ${ }^{37}$-postergando el ámbito extracontractual-y la irrupción de un nuevo anteproyecto de reforma han postergado el Project Catalá y el Project Terrè a un ámbito de referencia, en el que las sucesivas propuestas se mirarán y compararán.

De hecho, así ocurre con el nuevo Anteproyecto de Reforma del Código Civil Francés ${ }^{38}$ que, lejos de desocuparse de la cuestión que nos incumbe, prevé una nueva multa civil con un alcance mucho mayor que las ya expuestas.

En este sentido su artículo 1.266 reza:

«Cuando el autor del daño ha cometido deliberadamente una negligencia grave, en particular cuando esta última ha generado una ganancia o una ventaja económica para su autor, el juez puede condenarlo, mediante una decisión especialmente motivada, al pago de una multa civil.

Esta multa será proporcional a la gravedad de la conducta cometida, a la capacidad contributiva del autor o a los beneficios que hubiese obtenido de ella.

La multa no podrá exceder los 2 millones de euros. Sin embargo, podrá alcanzar diez veces la cantidad de ganancias o ahorros obtenidos con la conducta.

Si la persona responsable es una persona jurídica, la multa puede aumentarse hasta el 10\% del montante de la facturación mundial, excluyendo los impuestos, más alta obtenida durante un año fiscal cerrado y posterior al año financiero anterior al que se cometió la negligencia».

Esta multa se usará para financiar un fondo de compensación relacionado con la naturaleza del daño sufrido o, en su defecto, se destinará al Tesoro Público.» ${ }^{39}$

${ }^{37}$ Mediante la ordenanza de 10 de febrero de 2016 se incorporaron finalmente las modificaciones en materia de obligaciones y contratos al derecho positivo francés.

38 Avant-projet de Loi de Reforme de la Responsabilite Civile remitido por el Ministro de Justicia, el viernes, 29 de abril del año 2016, Direction des Affaires Civiles et du Sceau, consultable en http://www.textes.justice.gouv.fr.

39 Traducción propia del original. Texto original: «Lorsque l'auteur du dommage a délibérément commis une faute lourde, notamment lorsque celle-ci a généré un gain ou une économie pour son auteur, le juge peut le condamner, par une décision spécialement motivée, au paiement d'une amende civile. Cette amende est proportionnée à la gravité de la faute commise, aux facultés contributives de l'auteur ou aux profits qu'il en aura retirés. L'amende ne peut être supérieure à 2 millions d'euros. Toutefois, elle peut atteindre le décuple du montant du profit ou de l'économie réalisés. Si le responsable est une personne morale, l'amende peut être portée à $10 \%$ du montant du chiffre d'affaires mondial hors taxes le plus élevé réalisé au cours d'un des exercices clos depuis l'exercice précédant celui au cours duquel la faute a été commise. Cette amende est affectée au financement d'un fonds d'indemnisation en lien avec la nature du dommage subi ou, à défaut, au Trésor public.» 
Pues bien, poco se puede añadir a la claridad con que se expresa la propuesta. No sorprende el abandono de la «senda» de los daños punitivos para discurrir por caminos más conocidos, menos ajenos a la tradición jurídica francesa y, sobre todo, más refrendados por su corte constitucional -por el precedente del Código de Comercio-.

De este modo, adoptando una fórmula muy similar a la del Art. L442-6 del Código de Comercio, se propone una multa: (i) prevista para evitar supuestos en los que se obtenga un lucro de la causación del daño $0^{40}$; (ii) con una formulación abierta que permita dar cabida a multitud de supuestos de hecho; y (iii) que tenga en cuenta la gravedad de la conducta, el beneficio obtenido y la posición económica del agente del daño ${ }^{41}$.

Sin embargo, la propuesta no ofrece la multa civil de forma «gratuita»y, a cambio, exige al juzgador: (i) una motivación adecuada; (ii) el respeto de límites cuantitativos y (iii) que el montante se destine a fondos de compensación o el tesoro público en su integridad.

Cabe destacar en este punto, las diferencias con el Project Català ${ }^{42}$. Sin perjuicio de la obvia distinción en la naturaleza ex ante de la institución recogida en cada precepto, lo cierto es que el primer proyecto era más específico acerca de cuál debía ser el objeto de la especial motivación del juzgador. Así, en aquel se añadía que los «daños punitivos» debían específicamente diferenciarse de la amalgama de daños carentes de necesaria justificación, como hemos visto. En el actual Anteproyecto, sin embargo, no parece del todo claro si el juzgador ha de motivar los presupuestos de la conducta o el quantum de la multa (o ambos).

Asimismo, en el proyecto inicial no se hacía referencia a limitación cuantitativa alguna (siguiendo el esquema apriorístico de los daños punitivos) y pensando, probablemente, en la posterior tamización jurisprudencial.

Adicionalmente, en el Project Català solo se preveía que parte de los daños punitivos fuesen a parar al erario público mientras que, en el proyecto más moderno, a fin de desterrar completamente la sombra del enriquecimiento injusto, se destinan a un fin más específico (fondos de

${ }^{40}$ Algunos autores han criticado la falta de precisión terminológica en la descripción de la conducta. A modo de ejemplo, Mustafa MeKKI, «Le projet de réforme du droit de la responsabilité civile: maintenir, renforcer et enrichir les fonctions de la responsabilité civile». Gazette du palais: Recueil bimestral, vol. 136, núm. 3 (2016), págs. 1512-1514. En ese caso, el autor entiende que la confusión entre «falta o negligencia grave» («faute grave») y lo que hemos venido denominando «falta lucrativa» («faute lucrative») es heredada de los proyectos anteriores.

${ }^{41}$ Cuestiones, todas ellas que, como ya hemos comprobado ya estaban siendo parcialmente incorporadas por los jueces a sus decisiones en la práctica (vide ut supra apartado III).

42 No nos centraremos en el Project Terrè por ser un paso intermedio entre ambos $\mathrm{y}$ ofrecer una solución menos «disruptiva». 
compensación relacionados con el daño) y, en su defecto, el Tesoro Público.

Por último, llama la atención la supresión de cualquier referencia a la asegurabilidad de la eventual multa, lo que a priori debería suponer la posibilidad de su aseguramiento y, quizás, su devaluación como instrumento jurídico útil.

En definitiva, sin perjuicio del porvenir que finalmente reciba este precepto, no cabe la menor duda de que, después de años de maduración y con el precedente del Código de Comercio, tiene su génesis en una preocupación real y legítima del legislador y los juristas galos que ha permanecido en el tiempo. Es decir, que no es pasajera.

Cabe destacar, igualmente, la valentía con la que, en el ordenamiento vecino, se ha abordado la problemática tratando de aunar lo mejor de las instituciones ajenas con el respeto, sin dogmatismos, a la tradición jurídica propia. No en vano, recientemente, el ministro de justicia francés explicaba que ${ }^{43}$ :

«La idea es abrir un camino intermedio entre el camino civil clásico (centrado en la reparación de daños) y la forma penal (centrada en la sanción de los comportamientos).»

\section{CONCLUSIÓN}

En definitiva, resulta llamativo examinar el amplio debate judicial, doctrinal e incluso legislativo que sobre esta cuestión viene teniendo lugar desde hace más de una década en Francia. Y ello por comparación con la sencilla muestra de, si se nos permite la expresión, «desinterés» que, en general, se observa en nuestro ordenamiento, siendo como es tan similar al francés.

Es cierto que, hasta el momento y en el ordenamiento galo, determinadas soluciones jurídicas ex lege podían suscitar dudas sobre su naturaleza. También es cierto que, haciendo un cierto esfuerzo imaginativo, podían hallarse justificaciones para ellas distintas de la prevención y la punición. Así ocurría con las acciones en el ámbito de la propiedad intelectual (justificándolas con el Derecho de Enriquecimiento u otros «malabarismos»); las cláusulas penales (bajo el paraguas de la autonomía de la voluntad); las astreintes o las multas civiles más procesales (ocultándolas en el parapeto del derecho adjetivo).

Sin embargo, la incorporación de una multa civil al ordenamiento continental por antonomasia es toda una declaración contundente e indubitada de

43 Traducción propia del original en la presentación del 13 de marzo de 2017 que realizó el ministro de justicia francés, Jean-Jacques Urvoas sobre la reforma: «L'idée consiste à ouvrir une voie intermédiaire entre la voie civile classique (centrée sur la réparation des dommages) et la voie pénale (axée sur la sanction des comportements).» Accesible en http://www.justice.gouv.fr. 
que en el ámbito civil se ha trascendido la mera reparación. Y no es menos cierto que su incorporación también supone el reconocimiento tácito del problema jurídico-económico subyacente, las conductas lucrativas, y de la insuficiencia de los métodos clásicos para atajarlo.

Abandonando, para finalizar y por unos momentos, el ámbito investigador y adentrándonos en el opinativo, quizás sea oportuno recalar en aquel viejo refrán -tan propio, aunque con origen en el «hogar común» que es el mundo latino ${ }^{44}$ - que sugería poner en remojo las propias barbas cuando se viesen las del vecino cortar. Es innegable que existe una problemática concreta y real que, en otros ordenamientos -tanto ajenos a nuestra tradición jurídica como hermanos e inspiradores de la nuestra-, se ha reconocido abiertamente. Y en ellos se están buscando, insistentemente, mecanismos jurídicos más eficientes, nuevos y sin anclajes en dogmatismos de dudosa justificación para resolver esas cuestiones -como es, de hecho, la multa civil en el caso galo-. La duda, ahora, reside en si esperaremos, como hasta la fecha, nuestro turno en la barbería, detrás de nuestros vecinos, o si salimos a su encuentro y, si se quiere, debate.

De un modo u otro, la decisión sobre cómo afrontar estos problemas y la discusión sobre ello nos ha de llegar, porque ya se sabe lo que dice el viejo refrán: «cuando las barbas de tu vecino veas cortar, pon las tuyas a remojar».

\section{BIBLIOGRAFÍA}

Blanco Gómez, J. J., La cláusula penal en las obligaciones civiles: relación entre la prestación penal, la prestación principal y el resarcimiento del daño, Ed. Dykinson, Madrid, 2002.

CABANILlas SÁncheZ, A., «El Anteproyecto francés de reforma del Derecho de obligaciones y del Derecho de la prescripción. (Estudio preliminar y traducción)». Anuario de Derecho Civil, tomo LX, fasc. II (2007).

Díez Picazo, L., Fundamentos del Derecho Civil Patrimonial. Volumen V. La Responsabilidad Civil Extracontractual, $1^{\text {a }}$ edición, Madrid, Ed. Thomson-Reuters, 2011.

— «La doctrina del enriquecimiento injustificado» en Dos estudios sobre el enriquecimiento sin causa, $1^{\mathrm{a}}$ edición, Madrid, Edit. Civitas, 1988.

FASQUELLE, D. y MÉSA, R., «Les fautes lucratives et les assurances de dommages». Revue générale du droit des assurances, núm. 2005-02, (2005), págs. 351 y ss.

FERRANTE, Alfredo, «Una primera aproximación al Avant-Projet CATALA y a la nueva responsabilidad civil en el Derecho Francés», InDret 1/2008, Revista para el Análisis del Derecho, Barcelona (2008), págs. 12 y ss.

Goldberg, J.C.P., SeboK, A. J. y Zipursky, B. C., Tort Law. Responsibilities and Redress, $3^{\mathrm{a}}$ edición, Nueva York, Ed. Wolters Kluwer Law \& Business, 2012.

${ }^{44}$ Barbam propinqui radere, heus, cum videris, prabe lavandos barbula prudens pilos. 
Kemelmajer de CARlucci, A., «¿Conviene la introducción de los llamados «daños punitivos» en el Derecho Argentino?». Anales de la Academia Nacional de Derecho y Ciencias Sociales de Buenos Aires, núm. 31 (1993), págs. 88 y ss.

Koziol H. y Wilcox. V. et al., Punitive Damages: Common Law and Civil Law Perspectives, Tort and Insurance Law, vol. 25, $1^{\text {a }}$ edición, Viena, Ed. Springer, 2009.

Mustafa MeKKI, «Le projet de réforme du droit de la responsabilité civile: maintenir, renforcer et enrichir les fonctions de la responsabilité civile». Gazette $d u$ palais: Recueil bimestral, vol. 136, núm. 3 (2016), págs. 1512-1514.

PÉREZ Borges, E., «Un giro copernicano: la plurifuncionalidad de la responsabilidad civil en Italia». Revista de Actualidad Civil LA LEY, núm. 4, (2019).

Rodriguez Tapia, J.M., «Sobre la cláusula penal en el Código Civil». Anuario de Derecho Civil, núm. 2 (1993), pág. 550 y ss.

Starck, B., Roland, H. y Boyer, L., Droit civil - Les Obligations, tome 1: Responsabilité délictuelle, $5^{\mathrm{a}}$ edición, Paris, Ed. Paris Litec, 1996.

Vendrell Cervantes, C., Los derechos fundamentales de la personalidad incorporal y el mercado de los derechos de imagen. Tesis doctoral inédita, Universidad de Barcelona, 2010, Barcelona. 


\title{
LA MULTA CIVIL EN EL ORDENAMIENTO JURÍDICO FRANCÉS: «CUANDO LAS BARBAS DE TU VECINO...»
}

\author{
The civil fine in the French Legal Order: \\ "When your neighbor's bears ..."
}

\author{
Efrén Pérez Borges \\ Doctorando en Derecho Económico y de la Empresa \\ Universidad Pontificia Comillas
}

http://x.doi.org/10.18543/ed-67(2)-2019pp297-320

\section{Copyright}

Estudios de Deusto es una revista de acceso abierto, lo que significa que es de libre acceso en su in tegridad. Se permite su lectura, la búsqueda, descarga, distribución y reutilización legal en cualquier tipo de soporte sólo para fines no comerciales, sin la previa autorización del editor o el autor, siempre que la obra original sea debidamente citada y cualquier cambio en el original esté claramente indicado

Estudios de Deusto is an Open Access journal which means that it is free for full access, reading, search, download, distribution, and lawful reuse in any medium only for non-commercial purposes, without prior permission from the Publisher or the author; provided the original work is properly cited and any changes to the original are clearly indicated. 